\title{
Processo de trabalho na Estratégia de Saúde da Família: potencialidades da subjetividade do cuidado para reconfiguração do modelo de atenção
}

\author{
Work process in Family Health Program: the potential of \\ subjectivity of care for reconfiguration of the care model
}

Debora de Souza Santos ${ }^{1}$

Silvana Martins Mishima ${ }^{2}$

Emerson Elias Merhy ${ }^{3}$
${ }^{1}$ Faculdade de Enfermagem, Universidade de Campinas. R. Tessália Vieira de Camargo 126, Cidade Universitária. 13083-887 Campinas SP Brasil. deborass@unicamp.br

${ }^{2}$ Escola de Enfermagem de Ribeirão Preto, Universidade de São Paulo. Ribeirão Preto SP Brasil.

${ }^{3}$ Centro de Ciências da Saúde, Universidade Federal do Rio de Janeiro. Rio de Janeiro RJ Brasil.

\begin{abstract}
This is a study with a qualitative approach that aims to analyze the subjective dimension of the Family Health teams' practices conducted in order to reconfigure the care model, using the work process in health as the fundamental analytical category from the Marxist standpoint. The data gathering tool used was the focus group, applied in 13 Family Health teams in Ma ceió, Alagoas. Thematic analysis combined with principles of hermeneutics and dialectics was used for treatment and interpretation of the data. The results indicate that the user's needs identified by the teams are multiple and permeated by a lack of sympathetic care, and that the user repeatedly wishes to be "heard." The teams show that they are open to the use of soft technologies of compassionate care, although they do not legitimate them as instruments of their work. Clinical knowledge and techniques are prioritized in the work process, which limits the potential of its subjective dimension in order to (re)configure a care model which attends the user's needs and is sustained by integrated care.
\end{abstract}

Key words Primary health care, Delivery of health care, Family health, Health technology, Integrated care
Resumo Estudo de abordagem qualitativa com objetivo de analisar a potencialidade da dimensão subjetiva das práticas de equipes de Saúde da Família para reconfiguração do modelo de atenção, utilizando como referencial teórico-metodológico o processo de trabalho em saúde na perspectiva marxista. Teve como instrumento de coleta de dados o grupo focal, realizado em 13 equipes de Saúde de Família de Maceió, Alagoas. A análise temática, combinada a princípios da hermenêutica e dialética, foi utilizada no tratamento e interpretação dos dados. Os resultados apontam que as necessidades de saúde identificadas pelas equipes são múltiplas e permeadas pela carência afetiva do usuário que busca recorrentemente ser "ouvido". As equipes mostram-se abertas para o território das tecnologias leves de acolhimento, embora não as legitimem como instrumentos do seu trabalho. Saberes e tecnologias da clínica médica continuam sendo privilegiados no processo de trabalho, limitando a potencialidade de sua dimensão subjetiva para (re)configuração de um modelo que atenda as necessidades de saúde e ampare-se na integralidade da atenção.

Palavras-chave Atenção Primária à Saúde, Assistência à saúde, Saúde da família, Tecnologia em saúde, Integralidade 


\section{Introdução}

O processo de implantação do Sistema Único de Saúde (SUS) vem sendo acompanhado por discussões fomentadas no campo da Saúde Coletiva, que destacam dois nós críticos de análise: de um lado, o financiamento e a gestão e, de outro, a formação e o trabalho em saúde ${ }^{1}$. Porém, aqui, compreendidos como elementos em mútuas produções e não como pólos separados.

O exemplo mais recente desse movimento foi refletido na temática da $15^{\mathrm{a}}$ Conferência Nacional de Saúde, ocorrida em 2015: "Saúde pública de qualidade para cuidar bem das pessoas: direito do povo brasileiro". No documento oficial de lançamento da conferência ${ }^{2}$, o tema é justificado incorporando o significado de "Cuidar bem das pessoas mediante a realização e a valorização do trabalho multiprofissional e interdisciplinar, e a transformação das práticas de saúde".

O estudo das práticas de saúde tem se multiplicado com intuito de compreensão e avaliação dos processos de trabalho para proposição de novas modelagens de atenção, amparadas pelos princípios do SUS, tendo em vista a reversão do modelo ${ }^{3}$. Busca-se, portanto, superar o modelo biomédico hegemônico, que restringe o fazer em saúde a intervenções voltadas para a cura e controle dos sintomas, com progressiva fragmentação e medicalização do cuidado.

Inserindo-se neste campo, o presente trabalho se ampara no conceito de modelo de atenção nas perspectivas de Paim ${ }^{4}$ e Merhy ${ }^{5}$, que embora apresentem distinções de referenciais teóricos na produção de pesquisa sobre o SUS, compartilham da perspectiva comum de que o modelo corresponde à forma com que as tecnologias e saberes são organizados, dentro de um sistema, para responder às necessidades de saúde da população.

Nessa direção, a Estratégia Saúde da Família (ESF) é tida como mola propulsora de reorientação do modelo na Atenção Primária à Saúde (APS), ao propor atenção contínua a uma população de território definido, com o compromisso de proporcionar cuidado integral à saúde das famílias, por meio do trabalho interdisciplinar em equipe multiprofissional ${ }^{6,7}$.

Entretanto, embora a ESF se configure como um instrumento importante e mobilizador de mudanças, deve ser vista como campo de possibilidades, mais que modelo estruturado a ser incorporado acriticamente pelo país afora. Isso significa superar o ideário de formação de modelos ideais de saúde, defendendo a integralidade como princípio privilegiado para reorganização das práticas e reversão do modelo ${ }^{8}$. Integralidade implica no compromisso com uma atenção resultante de práticas direcionadas às necessidades objetivas e subjetivas das pessoas em seu contexto social, apreendidas e transformadas em ações por uma equipe multiprofissional, como a equipe de Saúde da Família.

Com este artigo, almeja-se contribuir com a produção científica atual sobre a discussão de modelos de atenção e trabalho em saúde, ao apresentar resultados de pesquisa referente à configuração, desafios e potencialidades do processo de trabalho de equipes de saúde da família de uma capital nordestina. O estudo dialoga com outras produções recentes relativas ao trabalho na $\mathrm{ESF}^{9-11}$ e a produção subjetiva do cuidado ${ }^{12,13}$, concentrando-se na potencialidade da dimensão subjetiva do processo de trabalho para mudança de modelo.

Para compreensão dessa temática, utilizou-se como referencial teórico-metodológico de análise a categoria trabalho na perspectiva marxista e suas implicações no campo da saúde. Esse recorte parte da premissa que o homem e todos os elementos que permitem sua (re)produção são marcados pela sua natureza histórica e social ${ }^{14}$. Todo trabalho, portanto, é visto como um processo, pois é constituído por fenômenos inter-relacionados, envolvendo um objeto, instrumentos, dispêndio de energia para realização de uma ação humana intencional que produzirá um produto.

O trabalho em saúde é aqui compreendido como uma prática social, carregando consigo finalidades que respondem a um projeto de sociedade em que estão imbricados concepções de saúde-doença-cuidado. O trabalho em saúde, portanto, se compõe amparado a tais concepções, de maneira, necessariamente, dialética ${ }^{15}$.

Merhy ${ }^{5}$ avança na compreensão do modo de produção em saúde, ao destacar particularidades que permitem sua renovação e reinvenção. Aponta a potencialidade do trabalho vivo em ato para produzir "ruídos", para além das normas instituídas pela lógica capitalista de produção, guardando elementos capazes de estabelecer outros projetos, com objetos, instrumentos e produtos diferentes daqueles instituídos e estruturados ${ }^{11}$.

Assim, ao buscar um modelo amparado na integralidade, é preciso transitar pelo território subjetivo do trabalho vivo em ato na saúde, potencializando redes vivas de cuidado que se desenham no território de tecnologias leves, sem deixar de considerar, contudo, a importância das demais tecnologias ${ }^{12,13,16}$. Tais tecnologias (leves) se apresentam como práticas de acolhimento, 
escuta e diálogo, significando, consensualmente para os autores até aqui apresentados, campo privilegiado para exercício do autogoverno e de reaproximação do fazer em saúde com os projetos de vida das pessoas ${ }^{17,18}$.

A referência à subjetividade do trabalho em saúde relaciona-se à produção subjetiva do cuidado, que segundo Franco e Merhy ${ }^{13}$ "é marcada por uma constante desconstrução e construção de territórios existenciais, segundo certos critérios que são dados pelo saber, mas também e fundamentalmente seguindo a dimensão sensível de percepção da vida, e de si mesmo, em fluxos de intensidades contínuas entre sujeitos que atuam na construção da realidade social”. A dimensão subjetiva do processo de trabalho, portanto, constitui-se como campo de força capaz de mobilizar e configurar o modo de produção, sendo historicamente construída e cujo núcleo operativo encontra-se no desejo processado inconscientemente, capaz de mover as pessoas na produção desse mundo, sendo por ele produzidas.

Tal subjetividade do trabalho é constitutiva das redes de atenção, estabelecendo linhas múltiplas de relação entre as "existências" de trabalhadores e usuários, numa lógica de fluxos-conectivos em prol de um determinado projeto terapêutico mais ou menos comprometido com a integralidade do cuidado.

A ESF tem um caráter fortemente burocrático, disciplinando o trabalhador e limitando sua capacidade criativa. Os protocolos padronizados, a lógica de produção por procedimentos/atendimentos e a agenda orientada para os programas nacionais são exemplos de captura do trabalho vivo pelo morto. Entretanto, a natureza instituinte do trabalho vivo em ato guarda o potencial de gerar linhas de fuga, onde se expressa a capacidade criativa de seus agentes ${ }^{12,13}$.

Estudo recentemente publicado ${ }^{3}$ revela que a produção científica brasileira sobre a capacidade da ESF em reorientar o modelo, entre 2002 e 2010, não apontou avanços que sustentem sua reversão, dado que reitera a importância de investigação do trabalho na APS como alavanca de mudança.

Nessa direção, em um esforço de enfoque na potencialidade, o presente estudo se concentra na reflexão de mudanças perceptíveis e possíveis no campo micropolítico das relações na ESF, com o objetivo de analisar criticamente as subjetividades manifestas na produção do cuidado das equipes de Saúde da Família, discutindo suas limitações e potências para (re)construção de um modelo amparado pelos princípios do SUS.

\section{Metodologia}

Estudo de abordagem qualitativa, que se voltou para a análise dos significados e sentidos presentes no contexto do processo de trabalho em saúde. Considerou-se essa estratégia uma das possíveis para captar a dinâmica do processo de trabalho das equipes de Saúde da Família, considerando seus elementos constituintes e a articulação permanente do trabalho vivo e do trabalho morto, bem como a expressão de subjetividade presente nesse processo ${ }^{19,20}$.

O olhar sobre o objeto de estudo aconteceu pela lente do referencial teórico de processo de trabalho em saúde, de maneira que a aproximação com conceitos da hermenêutica e dialética foi a opção adotada no processo de investigação, visto que constituem disciplinas da filosofia e ciências sociais que dialogam intimamente com o referencial teórico adotado.

O cenário do estudo foi a rede básica de saúde da capital do estado de Alagoas, onde o processo de trabalho de 13 equipes de Saúde da Família, pertencentes a 8 Unidades de Saúde da Família (USF), foi investigado. A definição das unidades ocorreu segundo critérios de "boas práticas", definidos pela coordenação de Saúde da Família da Secretária Municipal de Saúde, a qual indicou uma unidade de referência para cada Distrito Sanitário do município.

Os sujeitos da pesquisa foram os trabalhadores das equipes selecionadas, incluindo profissionais da equipe mínima da ESF e outros agregados heterogeneamente às equipes. No total, obteve-se a participação de 92 trabalhadores: agentes comunitários de saúde (38), técnicos e auxiliares de enfermagem (18), enfermeiras (11), médicos (9), dentistas (7), auxiliares administrativos (3), auxiliares de saúde bucal (2), assistentes sociais (2), porteiro (1) e auxiliar de limpeza (1). Os sujeitos eram, em sua maioria, do sexo feminino (77\%), idade acima de 36 anos (72,9\%), com curso universitário $(77 \%)$ e atuantes no serviço há mais de 10 anos $(59,5 \%)$.

A técnica de coleta de dados utilizada foi o Grupo Focal (GF), que se constituiu como uma das técnicas de entrevista coletiva sobre tema específico, mostrando-se muito útil na pesquisa de campo deste trabalho, por possibilitar amplo alcance da coleta junto aos trabalhadores e oportunizar a entrevista em seu contexto de trabalho. A coleta se estendeu por 14 meses, entre outubro de 2011 e novembro de 2012.

Para condução do grupo focal, foi utilizado um roteiro amparado no "fluxograma analisador 
do modelo de atenção de um serviço de saúde" ${ }^{5}$ (Figura 1).

A técnica de análise do material oriundo dos grupos focais foi a Análise de Conteúdo, na modalidade temática, contemplando as etapas de pré-análise, exploração do material e tratamento/interpretação dos dados ${ }^{21}$. Primeiramente, a leitura de cada entrevista de GF transcrita foi seguida da produção de uma síntese construída a partir das unidades de registro significativas (fragmentos das falas), que originaram as unidades de contexto. Esses elementos foram interpretados à luz do referencial teórico, agrupando-se em núcleos de sentido e, posteriormente, em temas que abrangiam um corpo de significações comuns e relevantes para investigação do objeto em estudo. Na etapa de tratamento do material, um mapa mental foi construído para organização e representação das informações, utilizando o programa FreeMind ${ }^{\circledR}$.

Conforme observado na Figura 2, três temas centrais emergiram da análise do material transcrito: I) capacidade crítica e criativa na organização do processo de trabalho; II) o cuidado tecido por laços de compromisso e vínculo; e III) tecendo um modelo de atenção: aproximações e contradições do processo de trabalho rumo à integralidade. O presente artigo concentra-se na discussão do segundo tema.

Importante salientar que o diferencial da análise se localizou no processo de construção dos temas, que se orientou por leitura do material que "abrisse a vista" para os contornos do contexto (hermenêutica) e as contradições (dialética) dos discursos que emanaram das experiências cotidianas dos trabalhadores na sua práxis.

Em síntese, a contribuição da hermenêutica está na compreensão, por meio da linguagem dos sentidos, significados e vivências dos indivíduos num determinado contexto. Por sua vez, a dialética visualiza essa linguagem como expressão dos antagonismos, presentes na realidade históricosocial conflitiva, de maneira que, uma vez desvelando o quadro real de desigualdades, é possível a apropriação dos instrumentos que possibilitem a transformação desse real ${ }^{22}$.

O projeto foi aprovado pelo Comitê de Ética em Pesquisa da Universidade Federal de Alagoas.

\section{Resultados e discussão}

Resultados e discussão são apresentados entrelaçados, em coerência ao referencial adotado. A narrativa foi construída a partir de dois núcleos temáticos: o primeiro, para entendimento das necessidades expressas pela comunidade, captadas e qualificadas pelo trabalhador como objeto de seu trabalho; e o segundo, para discussão das estratégias e tecnologias de cuidado, desenvolvidas pelas equipes como respostas às necessidades.

\section{Afetos e desabafos - as necessidades expressas pela comunidade}

Ao se falar da organização do processo de trabalho que atenda ao princípio da integralidade, sempre está colocada a questão das necessidades de saúde como objeto do trabalho. Essas serão expressões das pessoas que buscam cuidados, e que se constituem nos objetos de trabalho em saúde. A compreensão e apropriação do conceito de necessidades de saúde pelos trabalhadores contribuem para o desenvolvimento de práticas que vão além da intervenção nos corpos biológicos, ao tomar, como foco de intervenções, diversos aspectos que caracterizam a complexidade da vida humana $a^{4,23,24}$.

Segundo Matsumoto ${ }^{23}$, o complexo universo das necessidades de saúde engloba: "Boas condições de vida", "Ter acesso e poder consumir toda a tecnologia de saúde capaz de melhorar e

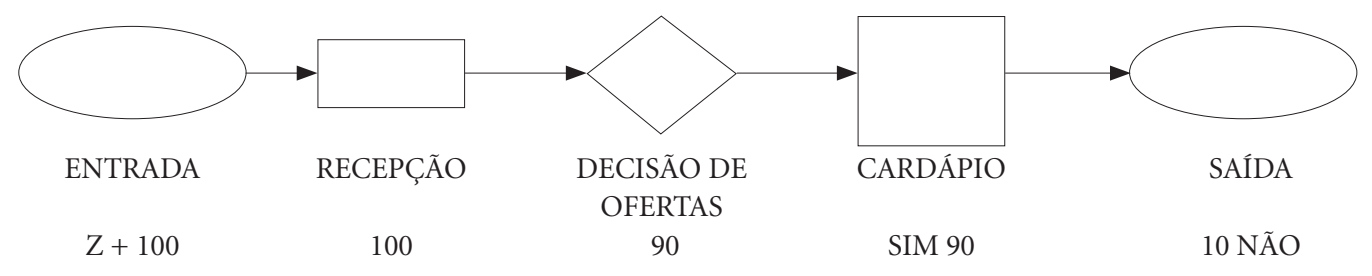

Figura 1. Fluxograma analisador do modelo de atenção de um serviço de saúde ${ }^{5}$. 

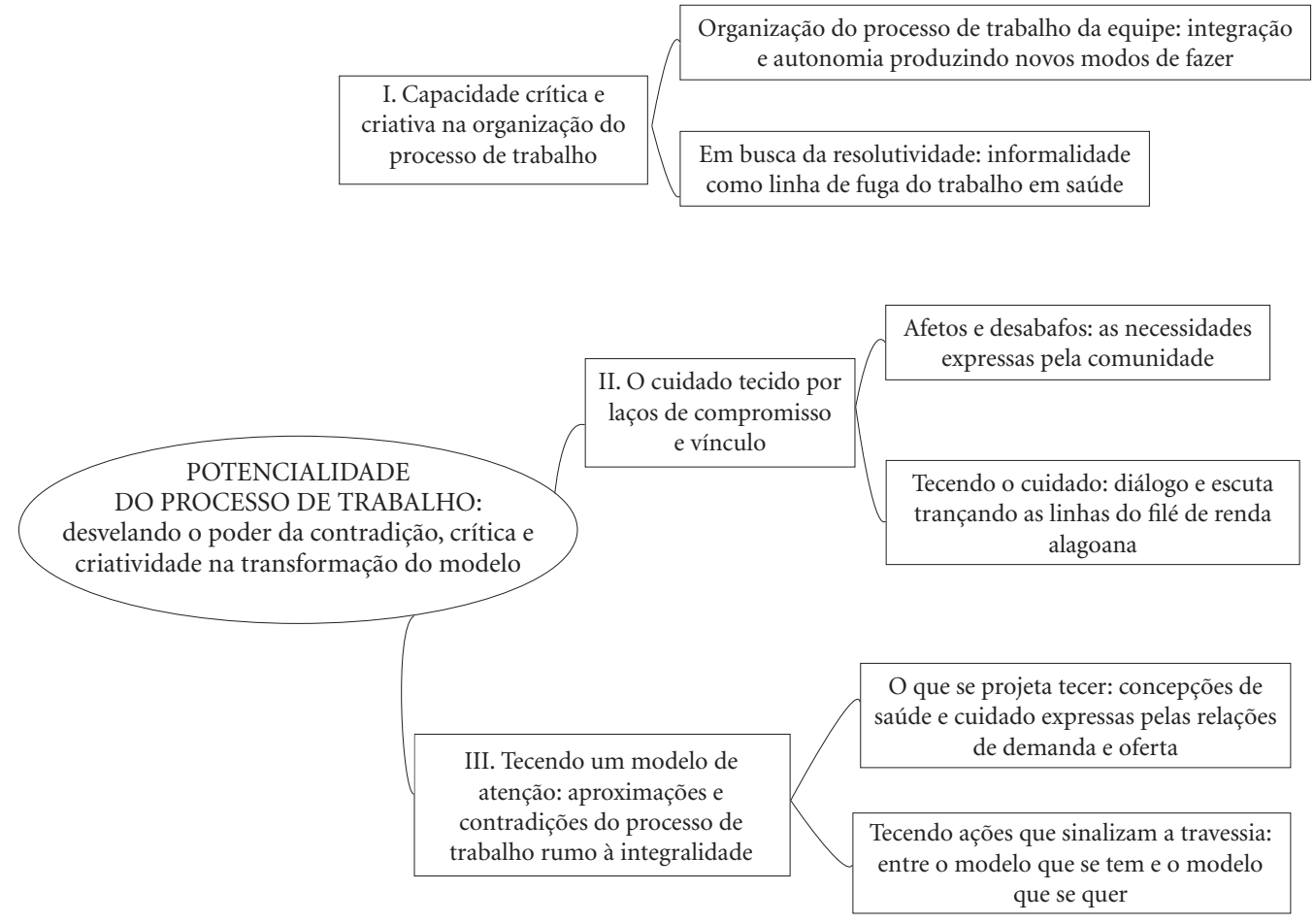

Figura 2. Mapa Temático construído com o programa FreeMind²2.

prolongar a vida", "Criação de vínculo (e)afetivo entre cada usuário e uma equipe ou trabalhador de saúde", "Cada pessoa ter graus crescentes de autonomia no seu modo de levar a vida".

Segundo os entrevistados, os usuários buscam maciçamente a unidade de saúde com queixa clínica, buscando solução para o sofrimento físico: febre, dor, pressão alta, ou manifestando desejo de "consumir saúde" com exames, consultas, medicamentos e outros serviços oferecidos no variado cardápio da USF.

$\mathrm{E}$ [enfermeira]: Aí eles vêm aqui querendo o tratamento, a cura, pra doença, mas no fundo mesmo é uma coisa que termina sendo bem emocional (Equipe 7).

Observa-se contradição no movimento de procura da comunidade pelos serviços. A partir das falas, é possível inferir que os usuários comumente utilizam a queixa clínica para entrar no serviço, pois é ela a moeda de troca para o atendimento, mas, uma vez inserido, revelam outras necessidades.

E [técnica de enfermagem]: em geral é uma queixa de dor, e quando a gente vai conversando mais a fundo, a gente vai vê que aquilo é uma carência. Tem muitas mães, que a gente já presenciou aqui, a questão assim... como tem uma criminalidade muito grande aqui, as mães que já perderam seus filhos, muitas estão depressivas. E elas desabafam com a gente, com a gente, com os ACS, com a médica, com a enfermeira (Equipe 10).

Os trabalhadores da ESF possuem um cardápio bem definido e pouco flexível, de maneira que os usuários encontram algum espaço para expressar suas dores, principalmente com o ACS, e, na pré-consulta, com o técnico de enfermagem. Nesses momentos, eles negociam sua entrada no serviço, buscando agendamento de consulta com médico, enfermeira ou dentista (com prioridade para o primeiro).

Nos encontros, os relatos apontam para manifestações diversas de sofrimento emocional e psíquico ligados às condições de profunda carência de ordens diversas (material, econômica, afetiva, educacional).

$\mathrm{R}$ [médica]: tem muitos hipertensos e diabéticos na área. E a gente percebe que a descompensação das doenças são ligadas às questões sociais, tipo 
assim, a gente orienta que pra ele tomar o remédio, a gente orienta em relação à alimentação. $E$ a alimentação normalmente não é seguida porque a oferta para eles não é de acordo com nossa orientação (Equipe 10).

Os relatos confirmam os indicadores de saúde de Maceió, marcados por profunda desigualdade social, desemprego, pobreza e violência ${ }^{25,26}$. Esse cenário revela que as necessidades da comunidade são múltiplas e profundas em relação a todas as dimensões de necessidades de saúde ${ }^{23}$. Isso significa dizer que os usuários chegam no serviço carentes de boas condições de vida, de tecnologias adequadas para manejo do sofrimento, relações de afeto e vínculo com equipe de saúde e desenvolvimento de autonomia para levar a vida.

A queixa clínica é real, porém, muitas vezes aparece como moeda para o atendimento. Os usuários precisam ser ouvidos. A necessidade de ser ouvido aparece muitas vezes como a primeira necessidade. Para tanto, se for necessário, o usuário irá mentir sobre sintoma ou patologia para entrar na unidade e ser ouvido.

E [enfermeira]: ontem mesmo chegou uma gestante dizendo que estava com sangramento, e eu disse que viesse pra eu olhar, mas quando eu olhei não tinha nada! Só queria o que... a pessoa estava estressada, teve uma discussão em casa com o marido, só é mesmo um desabafo! E às vezes eu pergunto, "por que você mentiu dizendo que era um sangramento?", ela diz "ah, porque se eu falasse que estava com esse problema, não iria ser atendida" (Equipe 13).

As pessoas adoecidas, marcadas pelo abandono, pela violência e pelo sofrimento, encontram no serviço de saúde um ambiente seguro, acolhedor, onde podem dar e receber afeto e, porque não dizer, permitem-se sentir mais humanos.

Os trabalhadores em suas falas compreendem as razões que levam as pessoas a comparecerem diariamente na unidade para serem ouvidas e acolhidas. Eles conhecem a história do bairro e as trajetórias e situações de vida de cada família, manifestando constantemente empatia e solidariedade pela comunidade. Isso pode ser observado no tom de carinho com que contaram as histórias trazidas pelos usuários, as risadas que compartilharam lembrando de casos peculiares e a percepção clara de que várias pessoas da comunidade sentem prazer em estar na USF.

Entretanto, nesse ponto, visualiza-se contradição na identificação da necessidade de saúde pelo trabalhador, pois embora ele perceba a importância da escuta e do acolhimento por parte da comunidade, não existe uma legitimação de que essa se constitui uma necessidade de saúde. Os relatos tendem a designar que, na verdade, muitas vezes os usuários não estão "sentindo nada", ou maximizam ou fingem a queixa clínica para serem ouvidos. Tal situação é aceita pelos trabalhadores, porém causa tensão e estresse no processo produtivo, visto que entendem que o problema real (patológico) não está sendo atendido.

A [auxiliar de enfermagem]: às vezes gera (conflito)! Até porque, às vezes, não têm como mais colocar [...]. Mas todo dia tem essa angústia de ter gente, gente, gente, gente... a gente diz, meu Deus tem paciente que vem aqui e a necessidade é só de falar, de ficar lá conversando (Equipe 12).

As expressões de subjetividade parecem não ser detectadas pelo trabalhador como necessidade de saúde, mas como produto da situação de vulnerabilidade social que fragiliza a comunidade emocionalmente. De maneira que, mesmo na emergência de necessidades subjetivas, são as tecnologias duras e leve-duras as mais valorizadas e (re)conhecidas pelas equipes. Resultado semelhante foi encontrado em estudo realizado com técnicos e auxiliares de enfermagem em uma cidade do estado de São Paulo, os quais reconhecem que os usuários possuem a necessidade de "conversar", embora não a identifiquem como objeto de seu trabalho ${ }^{10}$.

Entretanto, na produção cotidiana do cuidado, observa-se que a disponibilidade manifesta pelos trabalhadores para, a seu próprio modo, acolher e escutar o usuário potencializa o território de tecnologias leves, que, se por um lado, não rompe com o modelo hegemônico, por outro, abre caminho para a reconfiguração do modelo.

\section{Tecendo o cuidado - diálogo e escuta trançando as linhas do filé de renda alagoana}

A produção de renda de filé alagoana é trazida como esforço analógico para compreensão da potencialidade dos arranjos do trabalho em saúde rumo à mudança de modelo.

A confecção desse artesanato pode ser observada como prática difusa na cultura popular de Alagoas. Em 2014, o Conselho Estadual de Cultura registrou a renda de filé como patrimônio imaterial do estado ${ }^{27,28}$.

Seu processo de produção é desenvolvido artesanal e tradicionalmente por mulheres. Com o filé são fabricadas roupas, acessórios, lençóis, cortinas e diversos outros artigos que se moldam ao gosto da moda, da estação do ano e do 
"freguês". Os produtos se destacam pela beleza, profusão de cores e desenhos, que encantam pela originalidade das peças. Porém, o que a torna diferente de uma renda comum?

Nos mercados de artesanato de Maceió é possível distinguir com clareza os dois tipos de renda. A renda comum, geralmente aquela passível de reprodução na máquina, possui um trançado padrão que se repete em séries para produção do tecido. Pode ser colorida, mas a reprodução das cores seguirá sempre um padrão estabelecido $a$ priori.

Diferentemente, a renda filé é produzida manualmente pelas artesãs. Originalmente, as rendas começaram a ser cosidas a partir das redes de pescadores, de maneira que a artesã inicialmente confecciona uma rede com linha, que será utilizada como base do filé. Tal rede é esticada e fixada em uma moldura rígida, permitindo que a artesã crie desenhos variados conectados a essa base, mas não restritos a ela. Linhas de diversas cores são utilizadas para produzir desenhos variados, em tamanhos e formas, produzidos com liberdade criativa. Dessa maneira, dificilmente se encontra um artigo exatamente igual ao outro, pois as possibilidades de criação são infinitas.

O exemplo da rede de filé ajuda a analisar que cuidado está sendo tecido no contexto de trabalho das equipes investigadas. Já discutiu-se que as redes intersubjetivas são próprias da natureza instituinte do trabalho, porém, cabe agora distinguir como os artesãos do cuidado estão utilizando sua capacidade criativa para reversão do modelo.

Ao olhar para as equipes entrevistadas, observa-se que, em conformidade com o preconizado pela ESF, as equipes trabalham com território definido e população adstrita, o que permite uma relação próxima e habitual com as famílias, de maneira que os relatos expressam que a relação de vínculo e confiança estabelecida com a comunidade é uma característica sempre presente.

$\mathrm{N}$ [médica]: antes a gente tinha mais embate com essa comunidade, hoje a gente já não tem mais, hoje já tem uma amizade, já é uma conquista, porque precisa da confiança e de um compromisso nosso enquanto profissional (Equipe 2).

$\mathrm{O}$ vínculo é nutrido pelo cotidiano e parece configurar relações tão próximas que se assemelham às relações domésticas. As equipes citaram construir relações de "amizade" $e$ "intimidade" que diminuem a distância entre o profissional e o usuário, à medida que ambos são unidos, não apenas pela queixa de saúde (ou de doença) específica, mas também pelos laços de afeto que compartilham.
Entretanto, quanto mais próxima a relação construída, juntamente com sentimentos de confiança e amizade, outros dialeticamente imbricados também se manifestam, como raiva, ciúmes e ressentimentos.

Pela "intimidade", o usuário se sente com liberdade para cobrar atenção, atendimento no horário que lhe for conveniente, às vezes transitando no espaço da unidade com uma familiaridade que incomoda e dificulta o trabalho, visto que o trabalhador se sente dividido entre "agradar"/satisfazer a vontade do usuário e seguir a rotina do serviço.

Nesse contexto paradoxal em que se desenham as relações de vínculo, mediadas pelo afeto, a comunidade é pintada pelas equipes em diversas cores: boa, carente, sofrida, injustiçada, má, violenta, revoltada, mal agradecida, etc. Pode-se observar, portanto, que as equipes se importam com os usuários e isso parece gerar uma atenção compromissada, individualizada e marcada por contradições próprias dos encontros em que ocorrem enfrentamentos de singularidades.

B [enfermeira]: [...] como ela colocou ali, o pessoal vem aqui só pra sentar, porque aqui é a praça, aqui ele se arruma pra vir, aqui é o lazer, aqui a gente escuta, aqui a gente abraça, aqui a gente conversa, aqui a gente dá carão quando é necessário, chama a atenção quando é preciso, então ele recebe atenção aqui (Equipe 10).

Sobre a capacidade para oferecer essa atenção ao usuário, os trabalhadores demonstram entender que essa não é uma capacidade "aprendida” e sim própria de valores de solidariedade, empatia e amor pelo próximo, remetendo à ideia da dimensão ética do cuidado abordada por Franco e Merhy ${ }^{12,13 ~ " q u e ~ e ́ ~ o ~ m o d o ~ d e ~ s e r ~ d e ~ c a d a ~ u m ~ e m ~}$ relação ao outro".

M [auxiliar de enfermagem]: eu acho que é a humanização, é o amor ao nosso trabalho e ao ser humano. Não é uma questão nem de capacitação assim, não, eu acho que vai muito de cada profissional (Equipe 4).

Essa disponibilidade mais ou menos presente do trabalhador para o outro, mediado pelo afeto e intensificada pela profundidade do vínculo desenvolvido, se manifesta por uma constante valorização do diálogo com a comunidade, enquanto encontros de negociação, pactos e mediação de conflitos, que compõe a rede de subjetividade das práticas em saúde.

No fluxo do processo de trabalho, a entrada e recepção do usuário são os momentos privilegiados para acolhimento, escuta e tomada de decisão, visto que são pontos da linha do cuidado 
de tensão, requisitando o exercício de negociação para direcionamento do usuário dentro do serviço. A solicitação por encaixes no atendimento é frequente, o que gera conflito, e o diálogo é utilizado como tecnologia privilegiada para minimizar o estresse.

No espaço comunicacional das tecnologias leves, o acolhimento pode ser definido como rede de conversação capaz de conformar os instrumentos do trabalho em saúde, não se submetendo a eles. Nesse sentido, atuaria como estratégia que não se restringe a um momento do fluxo do cuidado, mas permearia todo o processo de trabalho gerido pelos fluxos de diálogo ${ }^{17,18}$. Por sua natureza de se fazer no encontro e na alteridade, o acolhimento não pode ser apreendido por nenhum saber específico, pois, pela riqueza de seu processo relacional e intersubjetivo, guarda em si certo mistério ${ }^{29}$.

Avançando nesta definição, o acolhimento é proposto como estratégia ética e política que institucionalmente viabiliza a concretização dos princípios fundamentais do SUS, de maneira a reverter a orientação dos serviços de centralidade de suas práticas nas ações programadas para um fazer orientado para as reais necessidades apresentadas pelos usuários, sem abandonar as ações de vigilância ${ }^{18}$.

Isso significa uma nova lógica de organização de trabalho, de potencialização dos encontros para: qualificação da escuta, no sentido de conhecer as necessidades e buscar soluções possíveis dentro das redes de cuidado disponíveis; ampliação e facilitação do acesso, especialmente na APS; estímulo ao exercício do trabalho multiprofissional, de maneira a ampliar a clínica. A operacionalização da proposta implica na orientação da equipe de Saúde da Família como equipe de referência, assumindo a responsabilidade de acolher os usuários nas suas demandas, ouvir, negociar e pactuar projetos de cuidado ${ }^{18}$.

No estudo, mesmo sem uma definição clara das equipes sobre a organização do processo de Acolhimento, os relatos indicam configuração de práticas que se aproximam das tendências apontadas pela literatura. A escuta acontece na sala de pré-consulta com auxiliar e técnico de enfermagem e continua no consultório, no domicílio, permeando o cotidiano.

Embora se perceba o reconhecimento da importância do uso dessas tecnologias leves no cotidiano do trabalho, as equipes, por vezes, manifestam despreparo ou falta de condições para o desenvolvimento do acolhimento de maneira satisfatória, tal qual é observado em outros estudos ${ }^{10,30}$.
De maneira recorrente, abordaram carência de outras categorias profissionais, além de inadequação dos espaços físicos das USFs para acolhimento dos usuários, de maneira a respeitar a privacidade e oferecer conforto. Nesse sentido, assim como alguns trabalhos relataram ${ }^{18,30}$, as equipes dão sinais de necessidade de investimento na qualificação do acolhimento, com a aquisição de mais profissionais (especialmente psicólogo), adequação do ambiente físico, desenvolvimento de educação permanente, apoio da gestão no suporte ao cuidado, dentre outros.

$\mathrm{Na}$ busca por superar os entraves na produção do cuidado, o trabalhador estabelece múltiplas conexões com universidades, instituições sociais presentes na comunidade e outros trabalhadores. Ou seja, utiliza da sua rede de relações interpessoal e institucional para conseguir atender às múltiplas e complexas necessidades encontradas.

$\mathrm{H}$ [assistente social]: muitas vezes me procuram por uma questão de uma criança que está fora da escola, a gente começa a conversar, muitas vezes eles chegam a denunciar maus-tratos na comunidade, crianças que estão sendo maltratadas pelos pais, usuários de drogas, pessoas que precisam de tratamento, muitas vezes na própria família desse usuário, e a conversa que a gente tem é muito rica nesse sentido, porque a gente descobre vários problemas que a gente pode ajudar, não muitas vezes aqui, mas na referência. A gente encaminha pessoas pra CAPS, que é o Centro de Atenção Psicossocial, para as escolas, uma criança especial que precisa de uma AAPE, que são as organizações não governamentais que muitas vezes fazem o papel que o governo deixa de fazer, e a gente consegue fazer essa ponte (Equipe 9).

Tais práticas de acolhimento, com essa potência de resposta às necessidades da comunidade foram observadas com vários graus de intensidade nas diferentes equipes. As equipes que demonstraram maior integração entre os trabalhadores e um vínculo mais forte com a universidade foram aquelas que relataram com detalhamento e clareza a obtenção de resultados positivos com o exercício cotidiano da intersetorialidade e interdisciplinaridade.

\section{Considerações finais}

O estudo sinaliza que a tendência da rede de subjetividade presente no cotidiano das equipes é de ampliação e fortalecimento, embora a política da ESF ainda atue no sentido de enquadrar e engessar as práticas. As linhas de cuidado vêm sendo 
desenhadas com as propriedades e finalidades até aqui discutidas, de maneira que mesmo estando assentadas na base estruturada preconizada pela Saúde da Família, não se restringem a ela.

Em síntese, dentre as potencialidades observadas, embora sejam as tecnologias duras e leveduras as mais legitimadas pelos trabalhadores como instrumentos de seu trabalho, os laços de afeto e amizade constroem o vínculo entre trabalhadores e usuários, dando vazão a um clima de intimidade que estreita as relações, tornando -as mais horizontais, abrindo-se às redes vivas de produção de existências.

A prática do acolhimento por meio da escuta e do diálogo marca o cotidiano de trabalho das equipes, embora não esteja definida como estratégia institucional de organização do trabalho. Os sentimentos de compromisso e vínculo esti- mulam práticas mais integradas, marcadas pela intersetorialidade e interdisciplinaridade.

O estudo contribui na compreensão das relações complexas presentes no processo de trabalho das equipes, sinalizando a potencialidade para o acolhimento e produção subjetiva de cuidado que atenda às diversas necessidades de saúde, ao mesmo tempo em que, contraditoriamente, demarca fragilidades relacionadas, principalmente, a não legitimação das necessidades subjetivas e das tecnologias leves como elementos de seu trabalho.

Espera-se que os resultados possam nortear estratégias de educação permanente em saúde que viabilizem o empoderamento dos trabalhadores no processo de cuidado, com valorização de sua dimensão subjetiva para reconfiguração do modelo de atenção.

\section{Colaboradores}

DS Santos participou da concepção do projeto, realização da pesquisa, análise e interpretação dos dados e redação do artigo. SM Mishima participou da concepção do projeto, análise e interpretação dos dados, revisão do artigo e aprovação da versão final. EE Merhy participou da análise dos dados, revisão crítica do artigo e aprovação da versão final. 


\section{Referências}

1. Teixeira CF. A mudança do modelo de atenção à saúde no SUS: desatando nós, criando laços. Saude Debate 2003; 27(65):257-277.

2. Brasil. Documento Orientador de apoio aos debates da 15a Conferência Nacional de Saúde. Conselho Nacional de Saúde [documento na internet]. 2015 Mai [acessado 2015 Ago 7]; [cerca de 31 p.]. Disponível em: http:// conselho.saude.gov.br/web_15cns/docs/05mai15_Documento_Orientador_15CNS.pdf

3. Angeli Silva L, Casotti CA, Lima Chaves SC. A produção científica brasileira sobre a Estratégia Saúde da Família e a mudança no modelo de atenção. Cien Saude Colet 2013; 18(1):221-232.

4. Paim JS. Modelos de Atenção à Saúde no Brasil. In: Giovanella L, Escorel S, Lobato LVC, Noronha JC, Carvalho AI, organizadores. Políticas e Sistema de Saúde no Brasil. Rio de Janeiro: Editora Fiocruz; 2008. p. 547-573.

5. Merhy EE. Em busca do tempo perdido: a micropolítica do trabalho vivo em saúde. In: Onoko R, Merhy EE, organizadores. Agir em saúde: um desafio para o público. $3^{a}$ ed. São Paulo: Hucitec; 2007. p. 71-112.

6. Giovanella L, Mendonça MHM. Atenção Primária à Saúde. In: Giovanella L, Escorel S, Lobato LVC, Noronha JC, Carvalho AI, organizadores. Politicas e Sistema de Saúde no Brasil. Rio de Janeiro: Editora Fiocruz; 2008. p. 575-625.

7. Brasil. Portaria no 2488 , de 21 de outubro de 2011. Dispõe sobre a Política Nacional da Atenção Básica. Diário Oficial da União 2011; 21 out.

8. Pinheiro R, Luz MT. Práticas eficazes X modelos ideais: ação e pensamento na construção da integralidade. In: Pinheiro R, Mattos RA, organizadores. Construção da integralidade: cotidiano, saberes e práticas em saúde. $4^{\text {a }}$ ed. Rio de Janeiro: LAPPIS-IMS/UERJ/CEPESC/ Abrasco; 2007. p. 7-34.

9. Matumoto S, Mishima S M, Fortuna CM, Pereira MJB, Almeida MCP. Discussão de famílias na estratégia saúde da família: processo de trabalho em construção. Rev esc enferm USP 2011; 45(3):603-610.

10. Matumoto S, Mishima SM, Fortuna CM, Cardoso OO. Processo de trabalho de auxiliares e técnicos de enfermagem na Atenção Básica à Saúde. Rev Bras Enferm 2011; 64(6):1087-1093.

11. Ferreira VSC, Andrade CS, Franco TB, Merhy EE. Community health agents' work process and restructuring. Cad Saude Publica 2009; 25(4):898-906.

12. Franco TB, Merhy EE. Cartografias do trabalho e cuidado em saúde. Rev Tempus Actas Saúde Coletiva 2012; 6(2):151-163.

13. Franco TB, Merhy EE. O reconhecimento de uma produção subjetiva do cuidado. In: Trabalho, produção do cuidado e subjetividade em saúde: textos reunidos. São Paulo: Hucitec; 2013. p. 151-171.

14. Marx K. O capital: crítica da economia política. $14^{\mathrm{a}}$ ed. Rio de Janeiro: Bertrand; 1994. Cap. 5.

15. Peduzzi M, Carvalho BG, Mandú ENT, Souza GC, Silva JAM. Trabalho em equipe na perspectiva da gerência de serviços de saúde: instrumentos para a construção da prática interprofissional. Physis 2011; 21(2):629-646.

16. Campos GWS. A mediação entre conhecimento e práticas sociais: a racionalidade da tecnologia leve, da práxis e da arte. Cien Saude Colet 2011; 16(7):3033-3040.
17. Takemoto MLS, Silva EM. Acolhimento e transformações no processo de trabalho de enfermagem em unidades básicas de saúde de Campinas. Cad Saude Publica 2007; 23(2):331-340.

18. Tesser CD, Poli Neto P, Campos GWS. Acolhimento e (des)medicalização social: um desafio para as equipes de saúde da família. Cien Saude Colet 2010; 15(Supl. 3):3615-3624.

19. Deslandes S F, Assis SG. Abordagens quantitativa e qualitativa em saúde: o diálogo das diferenças. In: Minayo MCS, Deslandes SF, organizadores. Caminhos do pensamento: epistemologia e método. $2^{\text {a }}$ ed. Rio de Janeiro: Fiocruz; 2008. p. 195-223.

20. Minayo MCS, Sanches O. Quantitativo-qualitativo: oposição ou complementaridade? Cad Saude Publica 1993; 9(3):239-262.

21. Minayo MCS. O desafio do conhecimento. $10^{\text {a }}$ ed. São Paulo: Hucitec; 2008.

22. Minayo MCS. Hermenêutica e dialética como caminho do pensamento social. In: Minayo MCS, Deslandes SF, organizadores. Caminhos do pensamento: epistemologia e método. 3a ed. Rio de Janeiro: Editora Fiocruz; 2008. p. $83-108$.

23. Matsumoto NF. A operacionalização do PAS de uma unidade básica de saúde do Município de São Paulo, analisada sob o ponto de vista das necessidades de saúde [dissertação]. Ribeirão Preto: Escola de Enfermagem, Universidade de São Paulo; 1999.

24. Campos CMS, Mishima SM. Necessidades de saúde pela voz da sociedade civil e do Estado. Cad Saude Publica 2005; 21(4):1260-1268.

25. Santos DS. Potencial criador e transformador do trabalho em saúde para (re) configuração de modelos de atenção [tese]. Ribeirão Preto: Escola de Enfermagem, Universidade de São Paulo; 2014.

26. Santos DS, Tenório EA, Brêda MZ, Mishima, SM. Processo saúde/doença e estratégia de saúde da família: o olhar do usuário. Rev Lat Am Enfermagem. 2014; 22(6):918-925.

27. Melo M. Bordado file ou renda file? Gazeta de Alagoas 2014 Ago 2 [acessado 2016 Fev 2]; [cerca de 01 p.]. Disponível em: http://gazetaweb.globo.com/gazetadealagoas/noticia.php? $c=249332$

28. Bordado é registrado como Patrimônio Imaterial de Alagoas. Gazeta de Alagoas 2014 Mar 31 [acessado 2016 Fev 2]; [cerca de 01 p.]. Disponível em: http://gazetaweb.globo.com/portal/noticia-old.php? $c=364979 \& e=6$

29. Ceccim RB, Merhy EE. Um agir micropolítico e pedagógico intenso: a humanização entre laços e perspectivas. Interface (Botucatu) 2009; 13(1):531-542.

30. Mitre SM, Andrade EIG, Cotta RMM. Avanços e desafios do acolhimento na operacionalização e qualificação do Sistema Único de Saúde na Atenção Primária: um resgate da produção bibliográfica do Brasil. Cien Saude Colet 2012; 17(8):2071-2085.

Artigo apresentado em 08/09/2015

Aprovado em 17/06/2016

Versão final apresentada em 19/06/2016 